\title{
MICA: UMA MOLÉCULA SECUNDÁRIA DE HISTOCOMPATIBILIDADE COM PAPEL NA REJEIÇÃO E NA IMUNOTOLERÂNCIA
}

Mica: a secondary histocompatibility molecule playing a role in the rejection and immunotolerance

Tatiana Michelon', Cristiane Sandri', Regina Schroeder', Jorge Neumann ${ }^{2}$

\section{RESUMO}

O gene MICA (Major histocompatibility complex class I chain-related gene A) codifica moléculas que apresentam similaridades estruturais com os antígenos HLA de classe I. No entanto, as moléculas MICA não se ligam à $\beta 2$-microglobulina, nem apresentam peptídeos aos linfócitos T. A transcrição dessas moléculas é induzida em condições de estresse celular. São expressas predominantemente na superfície de fibroblastos, células endoteliais e epiteliais, além de células tumorais. São moléculas que interagem com o receptor NKG2D presente em células NK e em linfócitos T $\gamma \delta$ e T $\alpha \beta$ CD8+, induzindo citotoxicidade. Por ser um sistema polimórfico, está envolvido em respostas aloimunes. Essas moléculas têm se revelado importantes no contexto dos transplantes de órgãos e de tecidos, induzindo a formação de aloanticorpos e participando de processos de rejeição, independentemente de anticorpos anti-HLA. Recentemente, demonstrou-se que moléculas MICA solúveis (sMICA) participam da evasão da resposta imune no contexto dos tumores e da gestação. Este artigo revisa a biologia das moléculas MICA, a importância clínica dos anticorpos anti-MICA em transplantes e discute as evidências do potencial de indução de imunotolerância das moléculas sMICA, ainda pouco exploradas clinicamente nos transplantes e em doenças com envolvimento do sistema imune.

Descritores: Anticorpos, Antígenos de Histocompatibilidade Menor, Transplante, Rejeição de Enxerto, Tolerância Imunológica

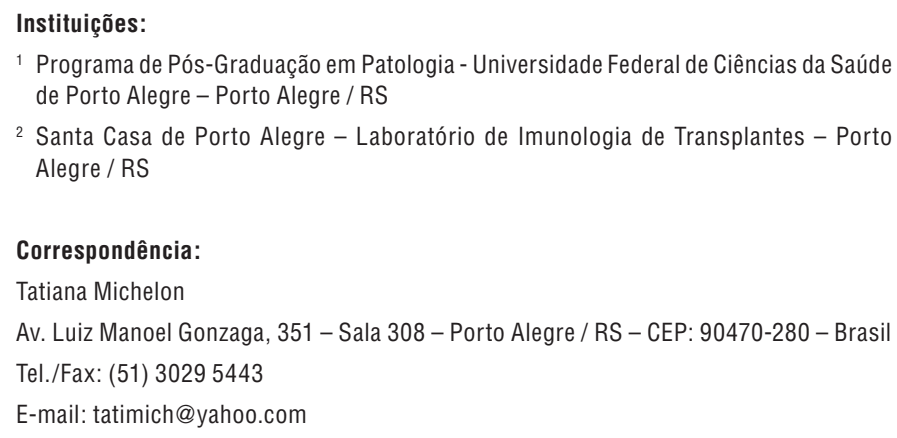

1 Programa de Pós-Graduação em Patologia - Universidade Federal de Ciências da Saúde de Porto Alegre - Porto Alegre / RS

2 Santa Casa de Porto Alegre - Laboratório de Imunologia de Transplantes - Porto Alegre / RS

Correspondência:

Tatiana Michelon

Av. Luiz Manoel Gonzaga, 351 - Sala 308 - Porto Alegre / RS - CEP: $90470-280$ - Brasil

Tel./Fax: (51) 30295443

E-mail: tatimich@yahoo.com

Recebido em: 02.06.2008

Aceito em: 30.06 .2008

\section{INTRODUÇÃO}

As principais moléculas de histocompatibilidade em humanos (conhecidas como HLA, do inglês Human Leukocyte Antigens) compreendem o sistema gênico mais polimórfico e são codificadas em uma região do braço curto do cromossomo 6, dentro do Complexo Principal de Histocompatibilidade (CPH). As proteínas HLA são divididas em duas classes expressas na membrana celular - classes I e II - com distribuição tissular extensa e responsáveis pela apresentação de peptídeos (próprios e não-próprios) ao sistema imune. Após o transplante, essas moléculas são alvo de reconhecimento pelo sistema imune do receptor, desencadeando todas as respostas imunes genericamente denominadas rejeição. ${ }^{1}$ Os produtos de outros genes de histocompatibilidade causam uma resposta menos intensa e são consequentemente conhecidos como Antígenos Secundários de Histocompatibilidade (ex: MICA e MICB). No entanto, as combinações de antígenos secundários também estão envolvidas em respostas imunes específicas e têm se revelado importantes no contexto de diversas patologias e situações peculiares de resposta imune em humanos, como nos transplantes de órgãos e tecidos. ${ }^{2}$

\section{MICA: ESTRUTURA GÊNICA E PROTEICA}

Os genes que codificam as proteínas MICA foram descritos independentemente em 1994 por dois grupos de investigadores. Estes genes também estão localizados no cromossoma 6 e codificam 
proteínas (antígenos) similares aos produtos derivados dos genes HLA de classe I, porém, possuem algumas particularidades estruturais, funcionais e de distribuição tissular. Por isso, foram denominadas MIC, contração de "MHC Class I Chain-related".

Ao contrário das moléculas HLA de classe I "clássicas", as moléculas MIC não estão associadas à $\beta 2$-microglobulina, ${ }^{4,5}$, são independentes de qualquer proteína transportadora (TAP) e não possuem função de apresentação antigênica ao sistema imune adaptativo. ${ }^{4,6}$ As peculiaridades da sua estrutura, revelando as homologias e diferenças com relação às moléculas HLA de classe I, foram esclarecidas somente a partir da definição da sua estrutura cristalográfica em 1999?

Estudos de mapeamento já identificaram 7 loci MIC (MICA até MICG), dos quais somente os loci MICA e MICB foram codificados até o momento. Da mesma forma que os genes HLA, os genes MIC são polimórficos, porém, em escala significativamente menor. Atualmente, existem 64 alelos MICA e 30 alelos MICB descritos. ${ }^{8}$

MICA e MICB estão localizados a 46,4 e 141,2 kb centromericamente ao HLA-B, respectivamente. ${ }^{9} \mathrm{O}$ locus MICA codifica polipeptideos de membrana de 383 a 389 aminoácidos com extensão que varia conforme a extensão das repetições de alanina na região transmembrana, possuindo massa molecular relativa de $43 \mathrm{kDa} .{ }^{10} \mathrm{O}$ locus MICB codifica uma proteína de 383 aminoácidos, atingindo $8 \%$ de similaridade à proteína MICA. ${ }^{9}$ A estrutura geral das moléculas MIC é semelhante àquela das moléculas HLA de classe I, possuindo 3 domínios $\alpha(\alpha 1$ a $\alpha 3)$, um domínio trans-membrana e outro domínio intracitoplasmático. A seqüência linear de aminoácidos possui $21 \%$ de identidade nos domínios $\alpha 1-2$ e de 32 a $36 \%$ no domínio $\alpha 3{ }^{10}$

\section{EXPRESSÃO CELULAR E FUNÇÃO BIOLÓGICA}

Os produtos dos genes MICA são expressos na superfície de células endoteliais, queratinócitos, fibroblastos e células mononucleares de sangue periférico. Também são expressos em epitélio gástrico e células trofoblásticas. ${ }^{2,3,5,9}$ Usualmente, as moléculas MICA não estão expressas na membrana de células $\mathrm{T}\left(\mathrm{CD} 4^{+}\right.$e $\left.\mathrm{CD} 8^{+}\right)$e células B. ${ }^{11}$ Apesar de as moléculas MIC estarem expressas na maioria das células de origem epitelial, ainda existe alguma dúvida com relação à sua expressão nas células que compõem os rins. ${ }^{4,12,13}$

As moléculas MICA atuam como ligantes para células Natural Killer $(\mathrm{NK})$, células $\mathrm{T}$ com receptor $\gamma \delta$ e células $\mathrm{T} \mathrm{CD} 8^{+}$que expressam o receptor NKG2D. Este é um receptor co-localizado com DAP10, uma proteína de sinalização trans-membrana ${ }^{14,15}$ envolvida nas respostas anti-tumorais, anti-virais, hematopoiéticas e de imunomodulação. ${ }^{16}$

Em linfócitos $\mathrm{T} \mathrm{CD}^{+}$e $\mathrm{CD}^{+}$essas proteínas não são expressas constitutivamente na membrana, mas podem ser isoladas a partir de lisados celulares ou após serem submetidas a determinados estímulos. ${ }^{\text {5, 11, } 17}$

Existe uma discreta diferença entre os tipos celulares que expressam constitutivamente os produtos MIC no citoplasma ou na superfície celular (Tabela 1: adaptada de Stephens et al, 2001). ${ }^{18}$ As proteínas de superfície podem ser hipo- ou hiper-expressas em células transformadas de vários tipos, particularmente as células de origem epitelial. Disto deriva o conceito de que as moléculas MIC representam marcadores de estresse epitelial, o que é consistente com sua super-expressão em membrana celular após indução por calor ou por infecção viral., 6, 19
A maioria dos estudos envolvendo as moléculas MICA nos transplantes tem explorado a importância do seu potencial alogênico, seja pela busca da máxima compatibilidade em transplantes de medula óssea, seja pela indução de aloanticorpos anti-MICA após transplantes de órgãos sólidos.

Todavia, sendo a expressão dessas moléculas modulada por mecanismos de estressse (infecções bacterianas, infecções virais, modificações tumorais, bem como episódios de rejeição), existe grande potencial intrínseco dessas moléculas interferirem com as respostas imunes do indivíduo, induzindo à citotoxicidade e secreção de citocinas. ${ }^{9}$

Em tumores, é reconhecida a importância das moléculas MICA expressas na membrana das células com transformação neoplásica (estresse) na indução de lise tumoral, a partir da sua interação com os receptores NKG2D de células NK e células T citotóxicas. 20

Em transplantes, ainda não se demonstrou o potencial das moléculas MICA do doador, hiper-expressas a partir do transplante (estresse), induzindo uma resposta citotóxica direta, ou seja, uma rejeição celular via ativação de células NK e células T. O cross-linking entre receptores NKG2D e as moléculas MICA auto-induzidas sugere a possibilidade desse mecanismo, uma vez que as células imunes reconhecem e atacam as células em estresse sem a necessidade da expressão de moléculas HLA de classe I ou do reconhecimento antigênico. ${ }^{21}$

\section{ANTICORPOS ANTI-MICA EM TRANSPLANTES}

\section{Transplante renal}

Do ponto de vista imunológico, três aspectos devem ser considerados imediatamente antes do transplante: a compatibilidade $\mathrm{ABO}$, o grau de compatibilidade HLA e a eventual presença de anticorpos anti-HLA pré-formados (específicos ou não contra o seu potencial doador). Centros de transplante renal, por ser o órgão sólido com a maior taxa de rejeição, necessitam dispor de avaliações específicas no período pré-transplante na escolha do melhor par doadorreceptor, na avaliação do risco imunológico pré-transplante e no acompanhamento da aloimunoreatividade e da imunossupressão ao longo do período pós-transplante. ${ }^{21-24}$

Nos últimos 5 anos, os antígenos MIC ganharam importância na avaliação da aloimunorreatividade do par doador-receptor, principalmente a partir da observação de que rejeições também ocorrem em casos de identidade HLA entre doador e receptor (pares HLA-idênticos). Além dos antígenos HLA habitualmente não pesquisados, tais como $\mathrm{C}$, DP e DQ, também os antígenos MICA podem induzir a formação de anticorpos, com repercussão clínica pós-transplante. ${ }^{18,25}$

A despeito da discussão sobre a expressão ou não das moléculas MICA na membrana de células renais, existe evidência de que essas moléculas estão presentes na membrana celular durante os eventos de rejeição aguda ou crônica após transplante. ${ }^{26}$ Também existe evidência de anticorpos específicos contra os antígenos MIC do doador em receptores de transplante renal. ${ }^{27}$

Publicações muito recentes demonstram que, à semelhança do que já se conhecia sobre anticorpos anti-HLA, os anticorpos anti-MICA podem ser formados a partir de processos imunizantes, como gestações e transplantes, e são mais frequentemente encontrados 
Tabela 1. Distribuição dos produtos de genes MICA humanos*

\begin{tabular}{|c|c|c|}
\hline Localização & Tipo de células & Detecção \\
\hline Núcleo (mRNA) & Promielócitos, monócitos, fibroblasto e epitélio & Northern blot \\
\hline Núcleo (mRNA) & Timo, próstata, testículos, sangue periférico, pulmões, fígado e intestino delgado & Northern blot \\
\hline Núcleo (mRNA) & Todos os tecidos com células epiteliais & Northern blot \\
\hline Citoplasma (proteína) & Neutrófilos e rim & IIF com anti-soro de coelho \\
\hline Citoplasma (proteína) & Isolado fresco de monócitos e queratinócitos & IIF e FC com anti-soro de coelho \\
\hline Superfície Celular (proteína) & Mucosas gástrica e intestina e córtex tímico & IIF com Ac monoclonais \\
\hline Superfície Celular (proteína) & Carcinoma de cólon e astrocitoma & IP e FC com Ac monoclonais \\
\hline Superfície Celular (proteína) & Fígado & IIF com anti-soro de coelho \\
\hline Superfície Celular (proteína) & Enxerto de pâncreas e rim & IIF com Ac monoclonais \\
\hline Superfície Celular (proteína) & HCMV-infecção & FC com Ac monoclonais \\
\hline Superfície Celular e Citoplasma (proteína) & Tumores epiteliais de pulmão, próstata, cólon, mama e ovário & IIF e FC com Ac monoclonais \\
\hline Superfície Celular e Citoplasma (proteína) & $\begin{array}{l}\text { Linhagens celulares transformadas derivadas de epitélio, queratinócitos, células T, célu- } \\
\text { las B, células endoteliais e monócitos }\end{array}$ & IP e FC com anti-soro de coelho \\
\hline Superfície Celular e Citoplasma (proteína) & Isolados frescos de células endoteliais e fibroblastos & IP e FC com anti-soro de coelho \\
\hline Superfície Celular e Citoplasma (proteína) & HCMV-infecção de células endoteliais e pneumonia intersticial & Imunocoloração de duas cores com Ac monoclonais \\
\hline
\end{tabular}

*modificada de Stephens et al; HCMV= citomegalovírus humano; IIF= imunofluorescência indireta; $\mathrm{IP}=$ imunoprecipitação; $\mathrm{Ac}=$ anticorpos; $\mathrm{FC}=\mathrm{citometria} \mathrm{de} \mathrm{fluxo}$

em pacientes que perderam enxerto renal do que em pacientes com enxerto funcionante. ${ }^{28}$ Em nosso meio, a prevalência de pacientes submetidos a transplante renal na vigência de anticorpos anti-MICA pré-formados é de $26 \%$ e seu efeito deve ainda ser analisado, considerando-se os demais fatores que podem interferir na sobrevida do enxerto. ${ }^{29}$

Estudos internacionais atuais demonstram que 11 a 20\% das perdas de enxertos ocorrem em pacientes que nunca desenvolveram anticorpos anti-HLA, sugerindo que antígenos não-HLA (especialmente MICA) possam estar relacionados a este fenômeno. ${ }^{28}$ Análises de sobrevida atuarial do enxerto no primeiro e quarto anos também indicam resultados significativos do envolvimento de anticorpos anti-MICA como um fator deletério. ${ }^{30}$

\section{Transplante pulmonar}

Em transplante pulmonar, a presença de anticorpos anti-HLA específicos, pré-formados ou surgidos após o transplante tem sido relatada em pacientes com rejeição aguda de alto grau ou refratários ao tratamento com corticosteróides. ${ }^{31}$ É importante a identificação de anticorpos anti-HLA pré-formados até mesmo em baixos títulos, por representarem risco de desenvolvimento de rejeição hiperaguda, rejeição mediada por anticorpo e bronquiolite obliterante e, conseqüentemente, menor sobrevida do pulmão transplantado. ${ }^{24,32}$

Existe a possibilidade de que o dano endotelial, expresso imunopatologicamente como uma síndrome de destruição de capilares septais possa também estar relacionado a anticorpos anti-MICA. A demonstração de que esse fenômeno é decorrente de mecanismo humoral mediado por anticorpo anti-endotélio suporta a hipótese de que anticorpos anti-MICA possam causar o mesmo tipo de dano, considerando a alta expressão de MICA em endotélio, especialmente em momentos de estresse. Desta forma, assim como anticorpos anti-HLA e anti-endotélio, também anticorpos antiMICA podem ter alguma implicação na fisiopatologia do dano crônico ao enxerto pulmonar. ${ }^{31,32}$

\section{Transplante cardíaco}

A presença de anticorpos anti-HLA classe I e II está associada ao desenvolvimento de rejeição aguda e crônica também após transplante cardíaco. ${ }^{33}$ Recentemente, vem se demonstrando a ocorrência de rejeição a despeito da inexistência de anticorpos anti-HLA, ${ }^{34,35}$ sugerindo o envolvimento de outros anticorpos, tais como anti-vimentina e anti-endotélio. Os principais candidatos na fisiopatologia desse tipo de rejeição são os anticorpos dirigidos contra as moléculas MICA e MICB, devido a seu grande polimorfismo 11 e potencial de sensibilização alogênica. ${ }^{36}$

A prevalência de anticorpos anti-MICA é da ordem de 30\% pré e pós-transplante cardíaco, ${ }^{33}$ sendo significativamente mais elevada entre pacientes que desenvolvem rejeição aguda grave (55-61\% x 6-14\%, na presença ou ausência de rejeição aguda, respectivamente, dependendo da técnica empregada). Na maioria dos casos, o aparecimento de anticorpos anti-MICA pós-transplante precede o diagnóstico de rejeição aguda, podendo auxiliar no manejo clínico. $^{37}$

\section{Transplante hepático}

A prevalência de anticorpos anti-HLA no pós-transplante hepático é de $24 \%$ e a de anticorpos anti-MICA é de $30 \%$ no pré e no pós-transplante. ${ }^{33}$ Sua relevância clínica ainda precisa ser melhor estudada.

\section{Transplante de medula óssea}

O polimorfismo dos genes MICA e MICB pode estar envolvido no transplante de medula óssea alogênico e na doença do enxerto contra o hospedeiro. 38 A hipótese que sugere a participação das moléculas MICA na doença do enxerto contra o hospedeiro deriva especialmente do reconhecimento da sua marcada expressão em tecidos de origem epitelial, principalmente no epitélio gastrointestinal. ${ }^{18}$ 
Embora o seu papel não tenha sido ainda muito bem esclarecido no contexto do transplante de medula óssea, já se demonstrou que a busca de doador não aparentado contemplando também a compatibilidade de genes não-HLA, como MICA e MICB ou através de tipificações alternativas de regiões específicas do genoma que compreendam estes genes ("bloco beta"), resultam em maior sobrevida do paciente. ${ }^{39,40}$

\section{SECREÇÃO DE MOLÉCULAS MICA (SMICA)}

Recentemente, demonstrou-se que alguns tipos celulares possuem capacidade não apenas de expressar moléculas MICA, mas também de secretá-las. Em condições basais, a maioria das células não dispõe desse potencial. Células de alguns tipos tumorais e células do sinciotrofoblasto o fazem com propósitos muito claros de "imunosobrevivência". 41,42

Em tumores, esse potencial de secreção de moléculas solúveis de MICA (sMICA) representa um mecanismo de evasão da resposta imune. As moléculas sMICA funcionam como inibidores competitivos dos receptores NKG2D, evitando o reconhecimento das moléculas MICA ligadas à membrana e reduzindo o potencial de expressão de receptores NKG2D pelas células NK e células T. ${ }^{43-46}$ Desta forma, as moléculas MICA podem ser implicadas não somente na indução de citotoxicidade (quando ligadas à membrana), mas também na sua supressão (quando solúveis). Apesar de ser clinicamente difícil a diferenciação entre as moléculas MICA secretadas e aquelas liberadas a partir da lise das células tumorais, os níveis de sMICA são frequentemente elevados em pacientes com doença neoplásica avançada, como carcinoma hepatocelular, câncer de colo uterino e carcinoma epidermóide da cavidade oral. ${ }^{47,48}$ Os pacientes com doenças benignas apresentam níveis intermediários, e indivíduos saudáveis apresentam níveis significativamente mais baixos. ${ }^{46}$

Na gestação, o desenvolvimento de eto semi-alogênico no organismo materno ainda permanece como uma questão fascinante e não completamente esclarecida pela Imunologia da Reprodução e dos Transplantes. De qualquer forma, os mecanismos envolvidos no aloreconhecimento, via moléculas HLA são muito peculiares na interface materno-fetal. Os tecidos embrionários possuem expressão muito diferenciada destas moléculas (HLA-C, -E, -F e $-\mathrm{G})$, resultando em um mecanismo de tolerância materno-fetal, local e sistêmico, altamente complexo. Um destes mecanismos é a secreção de sMICA pelas células do sinciotrofoblasto, regulando a expressão de receptores NKG2D em células mononucleares maternas e reduzindo, com isso, o potencial citotóxico contra os tecidos embrionários. Isto pode ser comprovado pelos níveis elevados de sMICA na circulação periférica de mulheres durante uma gestação normal. ${ }^{41}$

Em transplantes de órgãos sólidos, os estudos são escassos. Recentemente demonstrou-se que a presença sMICA na circulação periférica ao longo do primeiro ano pós-transplante cardíaco está relacionada ao desenvolvimento de tolerância imunológica ao aloenxerto. Provavelmente porque a presença de sMICA induz a redução da expressão de receptores NKG2D nas células do sistema imune com potencial citotóxico, resultando em redução do potencial de destruição do órgão transplantado por mecanismo de citotoxicidade mediado por células. Desta forma, existe uma correlação significativa entre a presença de moléculas sMICA e menor risco de rejeição ao coração transplantado. ${ }^{49}$ Ainda, na ausência de anticorpos anti-MICA, a presença de sMICA no póstransplante cardíaco constitui um excelente marcador de proteção contra eventos de rejeição aguda grave. ${ }^{50}$ Estudos em outros tipos de transplantes ainda não foram publicados.

\section{CONSIDERAÇÕES FINAIS / CONCLUSÃO}

Algumas células envolvidas em respostas imunes complexas, tais como tumor, gestação e transplantes, apresentam a capacidade de expressão e de secreção de moléculas MICA. O potencial imunizante dessas moléculas tão polimórficas em humanos já vem sendo bem explorado no contexto dos transplantes. Desta forma, anticorpos anti-MICA são relativamente freqüentes e provavelmente estejam envolvidos em processos de rejeição mediada por anticorpo.

Por outro lado, o conhecimento de que estas moléculas também podem ser secretadas por determinados tipos celulares tem esclarecido mecanismos de evasão da resposta imune anti-tumoral e imunotolerância materno-fetal. Portanto, o estudo da secreção de moléculas MICA (sMICA) e sua interação com as células NK e células $T$ pode auxiliar no entendimento dos mecanismos de aloimunotolerância, tão desejados após a realização de um transplante, e ainda auxiliar no desenvolvimento de novos fármacos e na compreensão da fisiopatologia de outras doenças com envolvimento do sistema imune.

\section{ABSTRACT}

The Major Histocompatibility Complex class I chain-related genes A - MICA - encodes molecules structurally similar to the HLA class-I. The major difference is the lack of $\beta 2$-microglobuline and peptide-binding. They are expressed on the membrane of the fibroblasts, endothelial, epithelial and tumor cells. The MICA transcription is induced by cellular stress. These molecules interact with NKG2D receptors expressed by NK cells and T $\gamma \delta$ and T $\alpha \beta-C D 8+$ lymphocytes, inducing cytotoxicity. The MICA system is polymorphic, and the molecules have been shown to be important in tissue and organ transplants, inducing the production of alloantibodies and graft rejection, regardless the HLA-antibodies. Recently, it has been demonstrated that the soluble MICA molecules (sMICA) are involved in the evasion of the immune response under tumoral and pregnancy conditions. This paper describes the MICA biology, pre- and post-transplant antiMICA antibodies, and also discussing the immunotolerance induction by the sMICA molecules.

Keywords: Antibodies, Minor Histocompatibility Antigens, Transplantation, Graft Rejection, Immune Tolerance 


\section{REFERÊNCIAS}

1. Michelon T \& Neumann J. Imunologia dos Transplantes In Fischer GB \& Schroeferneker ML: Imunologia Básica e Aplicada, Segmento Farma 2ed, Campo Belo-SP; 2007

2. Collins, R.W.M. Human MHC class I Chain Related (MIC) genes: their biological function and relevance to disease and transplantation. Eur J Immunogen. 2004;31:105-14

3. Statsny, P. Introduction: MICA/MICB in Innate Immunity, Adaptative Immunity, Autoimmunity, Cancer, and in the immune response to transplants. Hum Immunol. 2006;67:141-4

4. Groh V, Bahram S, Bauer S, Herman A, Beauchamp M, Spies T. Cell-stress-regulated human major histocompatibility complex class I gene expressed gastrointestinal epithelium. Procc Nat Acad Scienc USA. 1996;93:12445-50

5. Zwirner NW, Fernandez-Vina MA \& Statsny P: MICA, new polymorphic HLArelated antigen, is expressed mainly by keratinocytes, endothelial cells, and monocytes. Immunogenetics. 1998;47:139-48

6. Groh V, Steinle A, Bauer S \& Spies T. Recognition of stress-induced MHC molecules by intestinal epithelial gammadelta T cells. Science 1998; 279:1737-40

7. Li P, Willie ST, Bauer S, Morris DL, Spies T, Strong RK. Crystal structure of the MHC class I homolog MIC-A, a $\gamma \delta$ T cell ligand. Immunity. 1999;10:577-84

8. http://www.anthonynolan.org.uk, acessado em 14/07/2008

9. Bahram S. MIC genes: from genetics to biology. Adv Immunol 2000; 76:1-60

10. Bahram S, Bresnahan M, Geraghty DE \& Spies T. A second lineage of mammalian major histocompatibility complex class I genes. Procc Nat Acad Scienc USA. 1994;91:6259-63

11. Zwirner NW, Dole K \& Statsny P. Differential surface expression of MICA by endothelial cells, fibroblasts, keratinocytes, and monocytes. Hum Immunol. 1999;60:323-30

12. Groh V, Rhinehart R, Secrist H, Bauer S, Grabstein KH, Spies T. Broad tumorassociated expression and recognition by tumor-derived $\gamma \delta$ T cells of MIC and MICB. Proc Natl Acad Sci USA. 1999;96:6879-84

13. Leelayuwat C, Hollingsworth P, Pummer S, Lertmemongkolchai G, Thom G, Mullberg J, et al. Antibody reactivity profiles following immunization with diverse peptides of the PERB11 (MIC) family. Clin Exp Immunol. 1996;106:568-76

14. Bauer S, Groh V, Wu J, Steinle A, Phillips JH, Lanier LL, et al. Activation of NK cells and T cells by NKG2D, a receptor for stress-inducible MICA. Science. 1999;285:727-9

15. Wu J, Song W, Bakker AB, Bauer S, Spies P, Lanier LL, et al. An activating immunoreceptor complex formed by NKG2D and DAP10. Science. 199; 285:730-2

16. Trinchieri G: Biology of natural killer cells. Adv Immunol. 1989;47:187-376

17. Molinero LL, Marcos CY, Mirbaha F, Fainboim L, Statsny P, Zwirner NW: Codominant expression of the polymorphic MICA alloantigens encoded by genes in the HLA region. Eur J Immunogen. 2002;29:315-9

18. Stephens HAF: MICA and MICB genes: can the enigma of their polymorphism be resolved? Trends Immunol. 2001;22(7):378-85

19. Groh V, Rhinehart R, Randolph-Habecker J, Topp MS, Riddel SR, Spies T. Costimulation of CD $8+\alpha \beta$ T cells by NKG2D via engagement by MIC induced on virus-infected cells. Nat Immunol. 2001;2:255-60

20. Arreygue-Garcia NA, Daneri-Navarro A, Del Toro-Arreola A, Cid-Arregui A, Gonzalez-Ramella O, Jave-Suarez LF, et al. Augmented serum level of major histocompatibility complex class I-related chain A (MICA) protein and reduced NKG2D expression on NK and T cells in patients with cervical cancer and precursor lesions. BMC Cancer. 2008;8:16-25

21. Diefenbach A \& Raulet DH. Strategies for target cells recognition by natural killer cells. Immunol Rev. 2001;181:170-84

22. Neumann J. Avaliação Imunológica Pré-Transplante In Garcia VD, Abbud-Filho M, Neumann J \& Pestana JOM. Transplante de Órgãos e Tecidos, 2 ed, Segmentofarma, São Paulo, 2006
23. Michelon T, Schroeder R, Fagundes I, Canabarro R, Sporleder H, Rodrigues H, et al: Relevância clínica de baixos títulos de aloanticorpos preformados detectados em prova cruzada somente por citometria de fluxo no pré-transplante renal. J Bras Transpl. 2005;8:364 -71

24. Terasaki PI \& Ozawa M. Predicting kidney graft failure by HLA antibodies: a prospective trial. Am J Transplant. 2004;4(3):438-43

25. Neumann J, Kalil J, Brasile L, Cerilli J. Immunoblot analysis of sera specific vascular endothelial cells. Transplant Proc. 1989;21(1):700-1

26. Hankey KG, Drachember CB, Papadimitriou JC, Klassen DK, Philosophe B, Bartlett ST, et al. MIC expression in renal and pancreatic allograft. Transplantation. 2002;73(2):304-6

27. Zwirner NW, Marcos CY, Mirbaha F, Zou Y, Stastny P. Identification of MICA as a new polymorphic alloantigen recognized by antibodies in sera of organ transplant recipients. Hum Immunol. 2000;61:917-24

28. Mizutani K, Terasaki P, Shih RNJ, Pei R, Ozawa M, Lee J. Frequency of the MIC Antibody in Rejected Renal Transplant Patients without HLA Antibody. Hum Immunol. 2006;67:223-9

29. Michelon T, Sandri C, Ozawa M, Terasaki P, Neumann J. Pre-transplant anti-MICA antibodies and long-term follow-up in deceased donor kidney transplants. ASHI 33rd annual meeting -Annals 2007; 24-P: 70

30. Terasaki PI, Ozawa M \& Castro R. Four-year Follow-up of a prospective trial of HLA and MICA antibodies on kidney graft survival. Am J Transplant. 2006;7:408-15

31. Magro CM, Deng A, Pope-Harman A, Waldman WJ, Collins BA, Adams PW, et al. Humorally mediated posttransplantation septal capillary injury syndrome as a comom form of pulmonary allograft rejection: a hypothesis. Transplantation. 2002;74(9):1273-80

32. Magro CM, Ross PJr, Kelsey M, Waldman WJ, Pope-Harman A. Association of humoral immunity and bronchiolitis obliterans syndrome. Am J Transplant. 2003; 3(9):1155-66

33. Ozawa M, Terasaki PI, Lee JH, Castro R, Alberu J, Alonso C, et al. 14th International HLA and Immunogenetics Workshop: Report on the Prospective Chronic Rejection Project. Tissue Antigens. 2007;69:174-9

34. Reed EF, Demetris AJ, Hammond E, Itescu S, Kobashigawa JA, Reinsmoen NL, et al. Acute antibody-mediated rejection of cardiac transplantation. J Heart Lung Transplantation. 2006;25:153-9

35. Vasilescu ER, Ho EK, deLaTorre L, Itescu S, Marboe C, Cortesini R, et al. Anti-HLA antibodies in heart transplantation. Transpl Immunol. 2004;12:177-83

36. Zwirner NW, Marcos CY, Mirbaha F, Zou Y, Stastny P. Identification of MICA as a new polymorphic alloantigen recognized by antibodies in sera of organ transplant recipients. Hum Immunol. 2000;61:917-24

37. Suárez-Alvarez B, López-Vasquez A, Gonzales MZ, Fdez-Morera L, Díaz-Molina B, Blanco-Gelaz MA, et al. The relationship of anti-MICA antibodies and MICA expression with heart allograft rejection. Am J Transplantation. 2007;7:1842-48

38. Petersdorf EW, Shuler KB, Longton GM, Spies T, Hansen JA. Population study of allelic diversity in the human MHC class I- related MIC-A gene. Immunogenetics. 1999;49:605-12

39. Gaudieri S, Longman-Jacobsen N, Tay GK, Dawkins RL. Seqüence analysis of the MHC class I region reveals the basis of the genomic matching technique. Hum Immunol. 2001;62:279-85

40. Kitcharoen K, Witt CS, Romphruk AV, Christiansen FT, Leelayuwat C. MICA, $\mathrm{MICB}$, and MHC Beta Block Mathing in bone marrow transplantation outcome. Hum Immunol. 2006;67:238-46

41. Mincheva-Nilsson L, Nagaeva O, Chen T, Stendahl U, Antsiferova J, Mogren I, et al. Placenta-derived soluble MHC class-I chain-relarted molecules down-regulate NKG2D receptor on peripheral blood mononuclear cells during human pregnancy: a possible novel immune escape mechanism for fetal survival. J Immunol. 2006;176:3585-92 
42. Salih HR, GoehlsdorfD, Steinle A. Release of MICB molecules by tumor cells: mechanism and soluble MICB in sera of cancer patients. Hum Immunol. 2006;67:188-95

43. Groh V, Wu J, Yee C \& Spies T. Tumor-derived soluble MIC ligands impair expression of NKG2D and T-cells activation. Nature. 2002;419:734-8

44. Salih HR, Rammensee HG \& Steinle A. Cutting edge: down-regulation of MICA on human tumors by proteolytic shedding. J Immunol. 2002;169:4098-102

45. Doubrovina ES, Doubrovin MM, Vider E, Sisson RB, O'Reilly RJ, Dupont B, et al. Evasion from NK cell immunity by MHC class I chain-related molecules expressing colon adenocarcinoma. J Immunol. 2003;171:6891-9

46. Holdenrieder S, Stieber P, Peterfi A, Nagel D, Steinle A, Salih HR. Soluble MICA in malignant diseases. Int J Cancer. 2006;118:684-7

47. Jinushi M, Takehara T, Tatsumi T, Hiramatsu N, Sakamori R, Yamaguchi S, et al. Impairment of natural killer cell and dendritic cell functions by the soluble form of MHC class I-related chain A in advanced human hepatocellular carcinomas. J Hepatol. 2005;43,1013-20

48. Tamaki S, Sanefuzi N, Kawakami M, Aoki K, Imai Y, Yamanaka Y, et al. Association between soluble MICA levels and disease stage IV oral squamous cell carcinoma in japanese patients. Hum Immunol. 2008;69:88-93

49. Suárez-Alvarez B, López-Vasquez A, Díaz-Molina B, Bernardo-Rodriguez MJ, Alvarez-Lopez MR, Pascual D, et al. The predictive value of soluble Major Histocompatibility Complex Class I Chain-related molecule A (MICA) levels on heart allograft rejection. Transplantation. 2006;82:354-61

50. Suárez-Alvarez B, López-Vasquez A, Díaz-Peña R, Díaz-Molina B, Blanco-García RM, Alvarez-Lopez MR, et al. Post-transplant soluble MICA and MICA antibodies predict subsequent heart graft outcome. Transpl Immunol. 2006;17:43-6 